\title{
Distribution of the Indian Bustard Ardeotis nigriceps (Gruiformes: Otididae) in Gujarat State, India
}

\author{
Sandeep B. Munjpara ${ }^{1}$, B. Jethva ${ }^{2}$ \& C.N. Pandey ${ }^{3}$ \\ 1 Junior Research Fellow, GEER Foundation, Indroda Nature Park, P.O. Sector-7, Gandhinagar 382007, Gujarat, India \\ ${ }^{2}$ Asian Waterfowl Census Coordinator, Wetland International, C-101, Sarthak Apartment, Kh-0, Gandhinagar, Gujarat 382007, India \\ ${ }^{3}$ Additional Principal Chief Conservator of Forests, Sector-10, Gandhinagar, Gujarat 382007, India \\ Email: ${ }^{1}$ sandeepmunjpara@gmail.com (corresponding author), ${ }^{2}$ bharatjethva2000@yahoo.co.in, 3 pandeycn08@rediffmail.com
}

\begin{abstract}
The last surviving population of the Indian Bustard (IB) of Gujarat State was found to be distributed in the coastal grasslands of the Abdasa and Mandvi talukas of Kachchh District. The major part of the present distribution range of IB falls in the Abdasa Taluka and a small portion of this range falls in the Mandvi Taluka of Kachchh District in Gujarat. Geographically, this distribution of the IB is located on the northern coast of the Gulf of Kachchh. The total area of this distribution range of the IB in Gujarat covers a total of $996.4 \mathrm{~km}^{2}$ area. The entire area of the distribution range is more or less flat as compared to the surrounding typical topography of Kachchh District. The area within the distribution range of IB is mainly composed of grassland followed by open flat land.
\end{abstract}

Keywords: Distirbution, Indian Bustard, Kachchh, Naliya grasslands.

Distribution is the ecological occurrence of a species in geographical areas, and information on distribution of any animal plays an important role in ecological research because the size, shape, orientation of the

Date of publication (online): 26 September 2011

Date of publication (print): 26 September 2011

ISSN 0974-7907 (online) | 0974-7893 (print)

Editor: Rajiv S. Kalsi

Manuscript details:

Ms \# 02756

Received 08 April 2011

Final received 03 August 2011

Finally accepted 02 September 2011

Citation: Sandeep B. Munjpara, B. Jethva \& C.N. Pandey (2011) Distribution of the Indian Bustard Ardeotis nigriceps (Gruiformes: Otididae) in Gujarat State, India. Journal of Threatened Taxa 3(9): 2090-2094.

Copyright: (c) Sandeep B. Munjpara, B. Jethva \& C.N. Pandey 2011 Creative Commons Attribution 3.0 Unported License. JoTT allows unrestricted use of this article in any medium for non-profit purposes reproduction and distribution by providing adequate credit to the authors and the source of publication.

Acknowledgements: We are thankful to the Ministry of Environment and Forests, Government of India for financially supporting the present study. We sincerely acknowledge the valuable support received from Gujarat Forest Department. We extend our deep gratitude towards the fores officers of Kachchh Circle who constantly helped us out during various field visits. We are grateful to the staff members of GEER Foundation for helping and supporting our various activities for the project.

OPEN ACCESS | FREE DOWNLOAD distribution range and distribution pattern explains the conservation status of a species on a spatial scale. Such information is important for formulating future management strategies for the species under study. In view of the paucity of such information on the Critically Endangered (Bildlife Internation 2008) Indian Bustard (IB) [also known as the Great Indian Bustard (GIB)] in Gujarat, the present study was conducted to demarcate the boundaries of their distribution range in Gujarat based on systematic and scientific data collection.

\section{Study area}

This study was carried out in Naliya grasslands and surrounding areas in Abdasa as well as adjoining talukas (i.e. Mandvi, Lakhapat and Nakhtrana) of Kachchh District (Fig. 1). The area is located in the southwestern province of the district. On the southern side, it joins with the Gulf of Kachchh. Low precipitation and frequent drought condition in this area do not support the growth of big tree species; moisture from the air supports the growth of grass. Ecologically, this area is of the type of 5A/DS 4-Dry grassland with few scattered patches of 5A/DS 2-Dry Savannah forest as per Classification of Forest Types of India (Champion \& Seth 1968). The study area was composed of both continuous and discontinuous patches of grassland. A part of the area was covered with only grasses and forbs, while other areas had grass cover as well as scattered bushes of Acacia spp., Prosopis juliflora, P. cineraria, Zizyphus spp., Salvadora spp., and Caparis spp.

\section{Methods}

Preliminary information on the distribution of Indian Bustards in Gujarat was collected with the help of secondary literature and consultation with experienced ornithologists and nature lovers. The area under the intensive study (i.e. Naliya grassland) was 


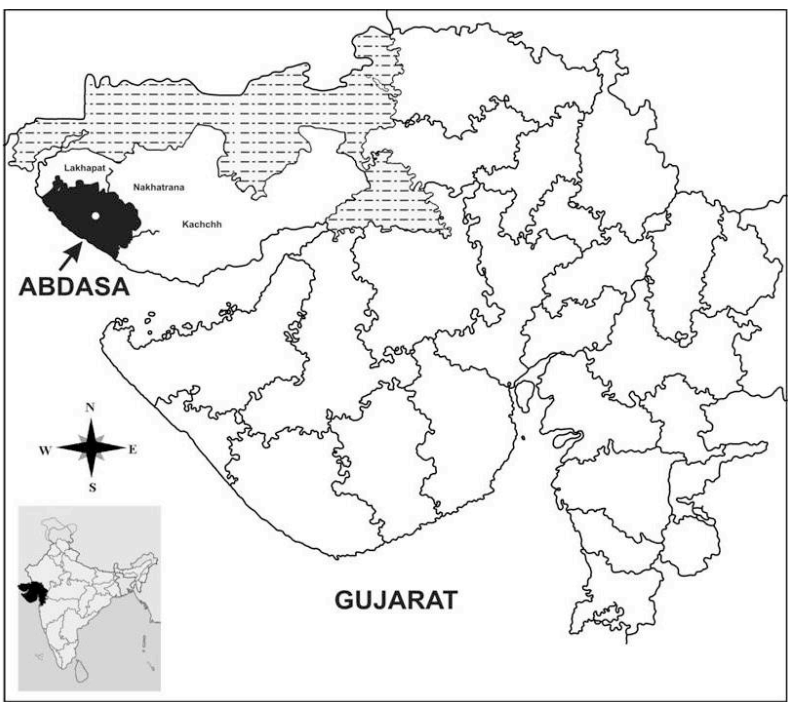

Figure 1. Stuey area

visited at least once a month. A total of 22 field visits were made from May 2006 to October 2007 and each field visit was of 4 to 10 days. The field visits were made to ensure data collection in all the seasons of the year as well as breeding and non-breeding phases of the species. Field observations were made with the help of powerful binoculars (Nikon-10X50) and spotting scope (Nikon-20X80). During each field visit, various physical and ecological parameters were noted upon sighting of the Indian Bustard [e.g. time of sightings, number of individuals (group size), their sex/age group (Male/Female/Juvenile), vegetation type where birds were sighted, activities of the birds, and the location of the birds]. The location of each sighting of the bustards was noted using GPS for studying distribution patterns and habitat preferences with respect to grass species, vegetation pattern etc.

\section{Results}

The population of Indian Bustards was found to be distributed in the coastal grasslands of the Abdasa and Mandvi talukas of Kachchh District (Fig. 2). This area is located in the southwestern province of Kachchh District in Gujarat (Fig. 2). A major part of the present distribution range of Indian Bustards falls in the Abdasa Taluka and a small portion of this range falls in the Mandvi Taluka of Kachchh District in Gujarat. The main locations of sightings of the species were grasslands and scrublands of some villages of Mandvi and Abdasa Taluka such as Bhanad, Kunathia, Naliya, Kalatalav, Jakhau, Jasapar, Gahdavada plot,
Bhavanipar, Budiya, Rampar, Jasapar, Vinghaber, Khauda, Lala, Lala Bustard Sanctuary, Lathedi, Bhachunda, Parjav, Ranpar, Sandhan, Suthari, Udheja Van and Vinjan (GPS locations in Table 1). Geographically, this distribution of Indian Bustard was located on the northern coast of the Gulf of Kachchh and the western-most part of the state and the country. This population, distributed in Kachchh District, is known to be the last surviving population of Indian Bustards in Gujarat State as the species is not found to breed or be localized in any other parts in the state. The total area of this distribution range of Indian Bustard in Gujarat covered $996.4 \mathrm{~km}^{2}$. The Indian Bustard's population was distributed in $0.51 \%$ of the total area of Gujarat State and $2.18 \%$ total area of Kutch District. The distribution range lie between $23^{\circ} 12^{\prime} 32.3^{\prime \prime}-$ $23^{\circ} 11^{\prime} 1.1^{\prime \prime} \mathrm{N}$ to $68^{\circ} 40^{\prime} 14.4^{\prime \prime}-69^{\circ} 9^{\prime} 26.4^{\prime \prime} \mathrm{E}$ in an eastwest direction and from $23^{\circ} 17^{\prime} 28.1^{\prime \prime}-23^{\circ} 0$ ' $8.8^{\prime \prime} \mathrm{N}$ to $68^{0} 54^{\prime} 25.3^{\prime \prime}-69^{0} 3^{\prime} 54.0^{\prime \prime} \mathrm{E}$ in a north-south direction. The distribution range of the Indian Bustard overlapped the revenue land of more than 37 villages, forest areas and "Kachchh Bustard Sanctuary" in Gujarat. The spread of the distribution range of Indian Bustards started from Mothala Village in the east to Jakhau Village in the west and from Tera Village in the north to Babhadai Village (of Mandvi tehsil) in the south. The entire area of the distribution range was more or less flat as compared to the surrounding topography typical of Kachchh District. The habitat use pattern within the distribution range of the Indian Bustard suggested that the majority of the area was composed of grassland (28\%) followed by open flat land (27\%).

\section{Discussion}

Apart from the present distribution range, the Indian Bustard was not sighted anywhere else in the state throughout the study period. The Indian Bustard once had a widespread distribution in Saurashtra and Kachchh (Fig. 3). In Kathiawar Peninsula, it was found in all areas except the forest areas of Gir, Girnar and Bardahills (Dharmakumarsinhji 1957). From 1950 to 1979 the distribution range of Indian Bustard was restricted tofive districts of Gujarati.e.Kachchh, Rajkot, Surendranagar, Jamnagar and Bhavnagar. Later they were sighted in Velavadar National Park, Bhavnagar in 1980 (Rahmani \& Manakadan 1990). By the end of the 1980s a few birds were recorded from Surendranagar and Rajkot (Rahmani \& Manakadan 1990) (Fig. 3). 


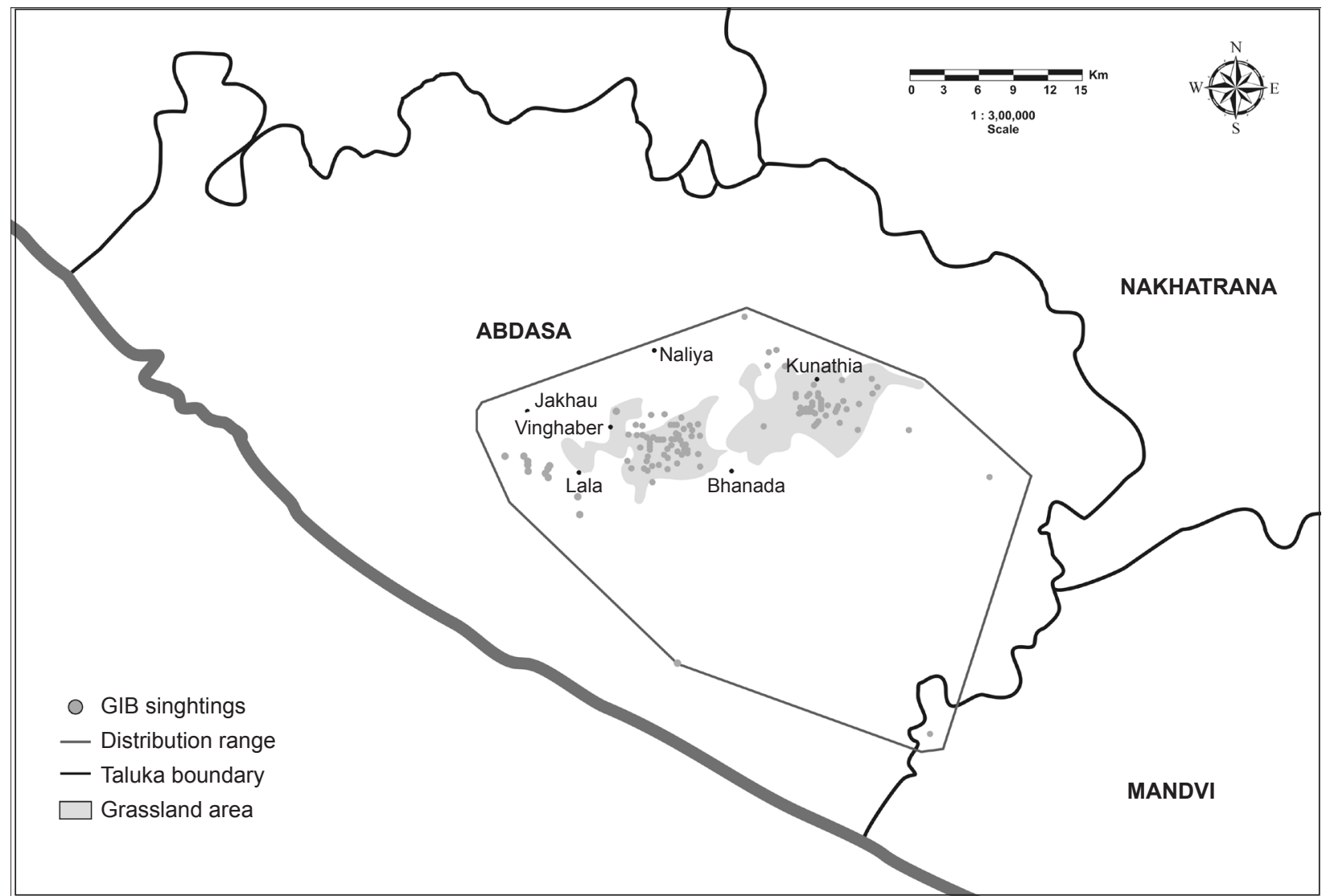

Figure 2. Annual distriution of Indian Bustard in Kachchh (Gujarat) between 2006-2007

In Jamnagar, it was last sighted from 1985 to 1986 at Ghoghera Talab and Kalyanpur Taluka. At the end of 1990 Indian Bustard became rare in most parts of the state and the distribution range was restricted to the Kachchh District. After the year 1990 no sighting records of the Indian Bustard were made from other areas of the state except Kachchh. However, recently, a pair of Indian Bustards was recorded for a short duration in the grasslands of Velavadar National Park in Saurashtra region in December 2005 (V. Rathod, RFO, Gujarat Forest Department pers. comm.). Apart from this, very recently in May 2008 one individual Indian Bustard was observed (Yogendra Shah pers. comm.) in the sparse saline grassland habitat of Little Rann of Kachchh in Surendranagar District of Gujarat. These recent records suggest that the Indian Bustard may be dispersing from the source population either from its distribution in Gujarat or from Rajasthan. It is also likely that the populations of Indian Bustard in the Thar Desert of Rajasthan and the grasslands of Kachchh are mixing. It is likely that the birds are moving along the marginal grass patches on the edge of Great
Rann and Little Rann of Kachchh in Banaskantha, Patan and Surendranager districts in Gujarat. The Indian Bustard is confirmed to be distributed only in six states of India that include Rajasthan, Madhya Pradesh, Andhra Pradesh, Karnataka, Maharashtra and Gujarat (Rahmani 2006). The Indian Bustard is not only locally extinct from its former range, it has also disappeared from the three sanctuaries declared 25 years ago for its protection (Rahmani 2006). One of these is Gaga Bustard Sanctuary, which lies in the Saurashtra peninsula in Gujarat. It is in this context that the present distribution range in Kachchh has great conservation significance as the present distribution range has been holding the population of the Indian Bustard for a long duration compared to many other habitats in Gujarat and across India (Fig. 3).

\section{REFERENCES}

BirdLife International (2008). Ardeotis nigriceps. In: IUCN 2011. IUCN Red List of Threatened Species. Version 
Table 1. GPS coordinates of Indian Bustard's sightings in study area

\begin{tabular}{|c|c|c|c|c|c|c|}
\hline & \multicolumn{3}{|c|}{ Latitude } & \multicolumn{3}{|c|}{ Longitude } \\
\hline & dd & $\mathrm{mm}$ & ss & dd & $\mathrm{mm}$ & ss \\
\hline 1 & 23 & 09 & 07.7 & 68 & 45 & 43.7 \\
\hline 2 & 23 & 09 & 50.3 & 68 & 45 & 39.1 \\
\hline 3 & 23 & 09 & 54.6 & 68 & 45 & 37.7 \\
\hline 4 & 23 & 10 & 29.9 & 68 & 49 & 32.4 \\
\hline 5 & 23 & 10 & 43.8 & 68 & 43 & 54.2 \\
\hline 6 & 23 & 10 & 46.6 & 68 & 42 & 56.7 \\
\hline 7 & 23 & 10 & 49.4 & 68 & 42 & 56.8 \\
\hline 8 & 23 & 10 & 53.6 & 68 & 43 & 04.5 \\
\hline 9 & 23 & 10 & 56.1 & 69 & 07 & 20.1 \\
\hline 10 & 23 & 10 & 56.8 & 68 & 49 & 18.8 \\
\hline 11 & 23 & 10 & 57.2 & 68 & 44 & 01.6 \\
\hline 12 & 23 & 11 & 00.4 & 69 & 07 & 09.7 \\
\hline 13 & 23 & 11 & 00.7 & 68 & 48 & 25.8 \\
\hline 14 & 23 & 11 & 01.1 & 68 & 50 & 19.3 \\
\hline 15 & 23 & 11 & 02.9 & 68 & 44 & 06.4 \\
\hline 16 & 23 & 11 & 06.5 & 68 & 42 & 55.5 \\
\hline 17 & 23 & 11 & 08.9 & 68 & 49 & 31.7 \\
\hline 18 & 23 & 11 & 10.3 & 68 & 49 & 51.0 \\
\hline 19 & 23 & 11 & 15.4 & 68 & 42 & 57.7 \\
\hline 20 & 23 & 11 & 17.9 & 68 & 50 & 48.4 \\
\hline 21 & 23 & 11 & 18.8 & 68 & 48 & 15.5 \\
\hline 22 & 23 & 11 & 20.5 & 68 & 49 & 13.3 \\
\hline 23 & 23 & 11 & 24.8 & 68 & 42 & 44.5 \\
\hline 24 & 23 & 11 & 25.4 & 68 & 41 & 46.6 \\
\hline 25 & 23 & 11 & 27.4 & 68 & 50 & 20.1 \\
\hline 26 & 23 & 11 & 31.8 & 68 & 49 & 16.8 \\
\hline 27 & 23 & 11 & 35.8 & 68 & 50 & 10.2 \\
\hline 28 & 23 & 11 & 37.9 & 68 & 51 & 05.5 \\
\hline 29 & 23 & 11 & 36.9 & 68 & 51 & 56.6 \\
\hline 30 & 23 & 11 & 40.8 & 68 & 51 & 21.4 \\
\hline 31 & 23 & 11 & 42.2 & 68 & 51 & 08.6 \\
\hline 32 & 23 & 11 & 43.8 & 68 & 50 & 48.5 \\
\hline 33 & 23 & 11 & 49.2 & 68 & 49 & 22.1 \\
\hline 34 & 23 & 11 & 49.8 & 68 & 50 & 24.3 \\
\hline 35 & 23 & 11 & 50.9 & 68 & 51 & 19.8 \\
\hline 36 & 23 & 11 & 51.2 & 68 & 48 & 53.2 \\
\hline 37 & 23 & 11 & 52.4 & 68 & 50 & 16.9 \\
\hline 38 & 23 & 11 & 52.9 & 68 & 50 & 18.2 \\
\hline 39 & 23 & 11 & 53.6 & 68 & 51 & 10.1 \\
\hline 40 & 23 & 11 & 59.2 & 68 & 51 & 16.1 \\
\hline 41 & 23 & 11 & 59.8 & 68 & 49 & 27.1 \\
\hline 42 & 23 & 12 & 00.0 & 68 & 50 & 31.2 \\
\hline 43 & 23 & 12 & 04.9 & 68 & 51 & 11.2 \\
\hline 44 & 23 & 12 & 05.6 & 68 & 51 & 06.2 \\
\hline 45 & 23 & 12 & 09.0 & 68 & 50 & 04.5 \\
\hline 46 & 23 & 12 & 09.8 & 68 & 50 & 08.2 \\
\hline 47 & 23 & 12 & 11.5 & 68 & 49 & 44.6 \\
\hline 48 & 23 & 12 & 11.6 & 68 & 49 & 59.6 \\
\hline 49 & 23 & 12 & 11.9 & 68 & 51 & 00.3 \\
\hline 50 & 23 & 12 & 12.5 & 68 & 49 & 16.3 \\
\hline 51 & 23 & 12 & 13.4 & 68 & 51 & 02.2 \\
\hline 52 & 23 & 12 & 13.8 & 68 & 50 & 41.0 \\
\hline 53 & 23 & 12 & 14.3 & 68 & 49 & 33.1 \\
\hline 54 & 23 & 12 & 14.4 & 68 & 50 & 56.2 \\
\hline 55 & 23 & 12 & 14.8 & 68 & 50 & 29.9 \\
\hline 56 & 23 & 12 & 15.7 & 68 & 49 & 35.3 \\
\hline 57 & 23 & 12 & 15.9 & 68 & 49 & 11.4 \\
\hline 58 & 23 & 12 & 19.5 & 68 & 48 & 42.2 \\
\hline 59 & 23 & 12 & 21.2 & 68 & 49 & 00.1 \\
\hline 60 & 23 & 12 & 22.1 & 68 & 52 & 00.8 \\
\hline
\end{tabular}

\begin{tabular}{|c|c|c|c|c|c|c|}
\hline & \multicolumn{3}{|c|}{ Latitude } & \multicolumn{3}{|c|}{ Longitude } \\
\hline 61 & 23 & 12 & 22.2 & 68 & 48 & 16.0 \\
\hline 62 & 23 & 12 & 23.7 & 68 & 50 & 58.8 \\
\hline 63 & 23 & 12 & 28.9 & 68 & 50 & 44.4 \\
\hline 64 & 23 & 12 & 33.3 & 68 & 51 & 37.1 \\
\hline 65 & 23 & 12 & 37.3 & 68 & 51 & 09.3 \\
\hline 66 & 23 & 12 & 42.8 & 69 & 00 & 17.8 \\
\hline 67 & 23 & 12 & 43.8 & 68 & 48 & 59.6 \\
\hline 68 & 23 & 12 & 44.2 & 69 & 03 & 01.3 \\
\hline 69 & 23 & 12 & 45.0 & 68 & 48 & 38.2 \\
\hline 70 & 23 & 12 & 47.6 & 68 & 50 & 26.3 \\
\hline 71 & 23 & 12 & 48.0 & 68 & 50 & 48.9 \\
\hline 72 & 23 & 12 & 49.3 & 68 & 50 & 35.9 \\
\hline 73 & 23 & 12 & 49.8 & 68 & 51 & 59.3 \\
\hline 74 & 23 & 12 & 50.0 & 68 & 51 & 52.0 \\
\hline 75 & 23 & 12 & 50.5 & 68 & 58 & 00.5 \\
\hline 76 & 23 & 12 & 51.6 & 68 & 55 & 20.4 \\
\hline 77 & 23 & 12 & 51.9 & 68 & 55 & 20.4 \\
\hline 78 & 23 & 12 & 59.8 & 68 & 59 & 20.8 \\
\hline 79 & 23 & 13 & 00.9 & 68 & 58 & 11.6 \\
\hline 80 & 23 & 13 & 04.1 & 68 & 51 & 03.0 \\
\hline 81 & 23 & 13 & 08.8 & 68 & 49 & 25.5 \\
\hline 82 & 23 & 13 & 13.2 & 68 & 50 & 06.7 \\
\hline 83 & 23 & 13 & 15.8 & 68 & 47 & 36.6 \\
\hline 84 & 23 & 13 & 17.4 & 68 & 57 & 10.4 \\
\hline 85 & 23 & 13 & 19.4 & 68 & 57 & 23.9 \\
\hline 86 & 23 & 13 & 20.8 & 68 & 58 & 04.9 \\
\hline 87 & 23 & 13 & 24.5 & 68 & 57 & 47.8 \\
\hline 88 & 23 & 13 & 25.4 & 68 & 59 & 05.2 \\
\hline 89 & 23 & 13 & 25.5 & 68 & 57 & 27.5 \\
\hline 90 & 23 & 13 & 27.1 & 68 & 57 & 28.0 \\
\hline 91 & 23 & 13 & 30.4 & 68 & 59 & 10.9 \\
\hline 92 & 23 & 13 & 30.7 & 68 & 58 & 21.1 \\
\hline 93 & 23 & 13 & 33.4 & 68 & 57 & 14.1 \\
\hline 94 & 23 & 13 & 33.5 & 68 & 59 & 41.7 \\
\hline 95 & 23 & 13 & 36.1 & 68 & 57 & 52.8 \\
\hline 96 & 23 & 13 & 37.7 & 68 & 59 & 16.3 \\
\hline 97 & 23 & 13 & 38.9 & 68 & 58 & 25.1 \\
\hline 98 & 23 & 13 & 39.8 & 68 & 58 & 42.6 \\
\hline 99 & 23 & 13 & 44.5 & 69 & 00 & 17.5 \\
\hline 100 & 23 & 13 & 45.8 & 68 & 58 & 21.0 \\
\hline 101 & 23 & 13 & 46.6 & 68 & 57 & 53.2 \\
\hline 102 & 23 & 13 & 48.9 & 68 & 58 & 23.1 \\
\hline 103 & 23 & 13 & 50.7 & 68 & 59 & 30.9 \\
\hline 104 & 23 & 13 & 56.9 & 68 & 57 & 03.8 \\
\hline 105 & 23 & 14 & 00.0 & 68 & 58 & 12.3 \\
\hline 106 & 23 & 14 & 02.7 & 68 & 57 & 38.8 \\
\hline 107 & 23 & 14 & 05.6 & 68 & 57 & 48.0 \\
\hline 108 & 23 & 14 & 08.1 & 68 & 58 & 14.6 \\
\hline 109 & 23 & 14 & 11.3 & 69 & 01 & 03.2 \\
\hline 110 & 23 & 14 & 25.1 & 69 & 01 & 16.7 \\
\hline 111 & 23 & 14 & 27.3 & 68 & 58 & 00.5 \\
\hline 112 & 23 & 14 & 42.2 & 68 & 59 & 26.4 \\
\hline 113 & 23 & 14 & 44.1 & 69 & 01 & 00.0 \\
\hline 114 & 23 & 15 & 09.1 & 68 & 56 & 27.3 \\
\hline 115 & 23 & 15 & 11.3 & 68 & 55 & 31.3 \\
\hline 116 & 23 & 15 & 42.6 & 68 & 55 & 33.7 \\
\hline 117 & 23 & 15 & 49.8 & 68 & 55 & 56.2 \\
\hline 118 & 23 & 17 & 09.8 & 68 & 54 & 14.4 \\
\hline
\end{tabular}



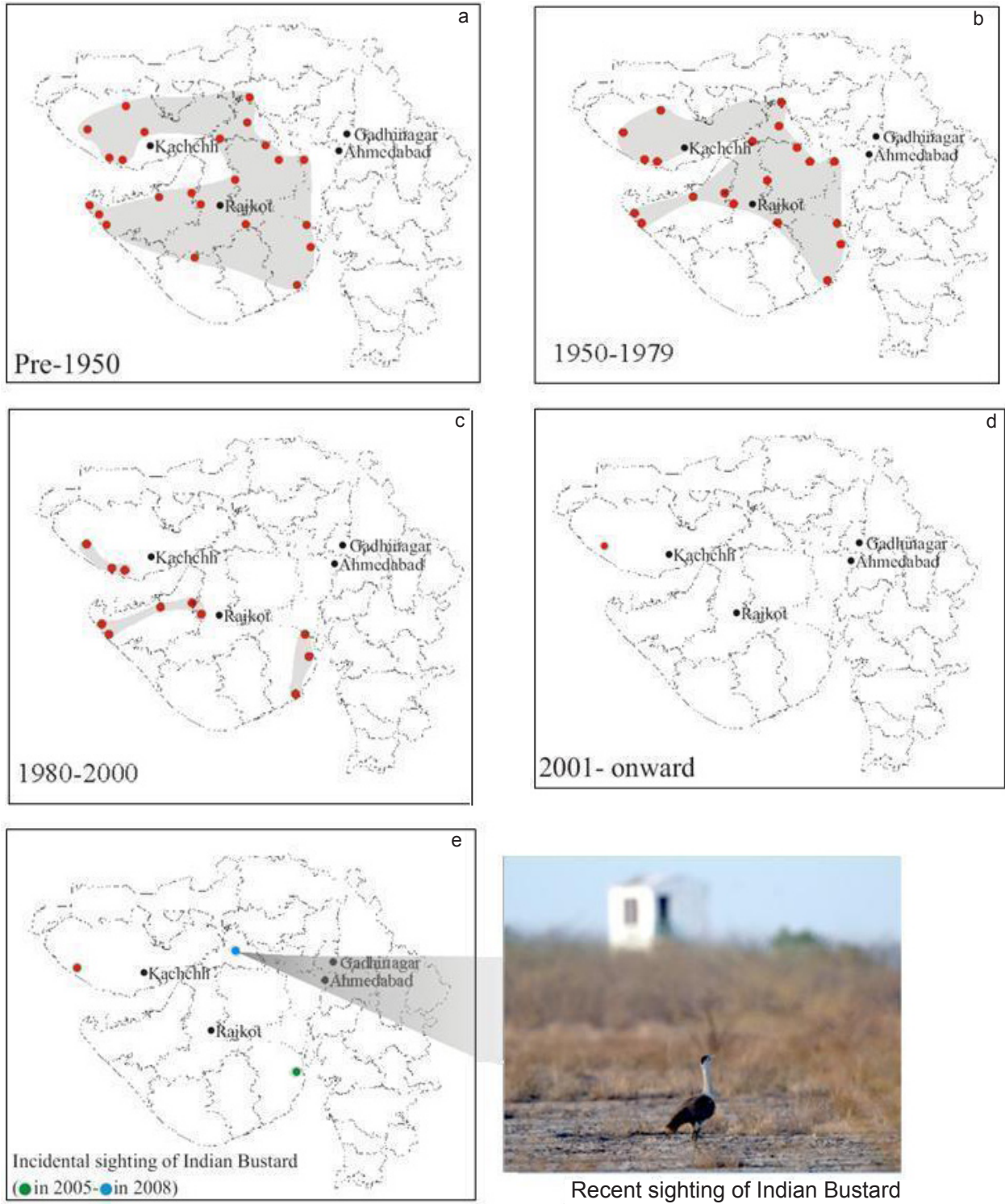

Recent sighting of Indian Bustard in Little Rann of Kuchchh

\section{Distribution range of Indian Bustard}

- Locations/site of occurrence of Indian Bustards

Figure 3. Shrinking of distribution range of Indian Bustard in Gujarat. Maps adapted from 3(a) - Dharmakumarsinhiji (1957): 3(b) - Rahmani \& Manakadan (1990); 3(c) - Rahmani \& Manakadan (1990) and Rahmani (2001); Incidental sightings of the species of 2005 and 2008 have not been shown in the map which indicates 3(d) - distribution from 2001 onwards; 3(e) - Based on present study and incidental sighting.

2011.1. <www.iucnredlist.org>. Downloaded on 16 September 2011.

Champion, H.G. \& S.K. Seth (1968). A Revised Survey of Forest Types of India. Government of India Publication, New Delhi, 404pp.

Dharmakumarsinhiji, K.S. (1957). Ecological Study of the Indian Bustard Ardeotis nigriceps (Vigor) (Aves: Otididae) in Kathiawar Peninsula, Western India. Journal of Zoological Society of India 9: 140-152.
Rahmani, A.R. \& R. Manakadan (1990). The past and present distribution of the Indian Bustard Ardeotis nigriceps (Vigors) in India. Journal of the Bombay Natural History Society 87: 175-194.

Rahmani, A.R. (2001). The Godawan Saga: Great Indian Bustards in decline. Sanctuary (Asia) 21(1): 24-28

Rahmani, A.R. (2006). Need to Start Project Bustards. Bombay Natural History Society, Mumbai, 20pp. 